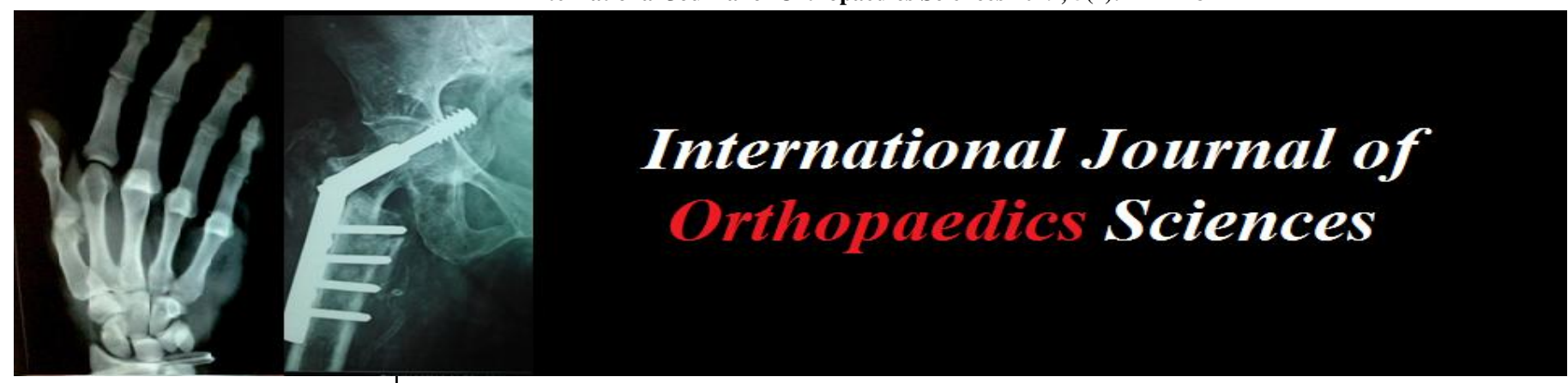

E-ISSN: 2395-1958

P-ISSN: 2706-6630

IJOS 2019; 5(4): 774-778

(C) 2019 IJOS

www.orthopaper.com

Received: 01-08-2019

Accepted: 03-09-2019

Sidhartha Samal

Assistant Professor, Department of Orthopaedics, IMS and SUM Hospital, Siksha 'O' Anusandhan University, K8, Kalinga Nagar, Bhubaneswar, Odisha, India

Santosh Kumar Sahu

Assistant Professor, Department of Orthopaedics, IMS and SUM

Hospital, Bhubaneswar, Odisha, India

Swayamprabha Sahoo

Medical Research Laboratory, IMS and SUM Hospital, Siksha ' $\mathrm{O}$ ' Anusandhan University, K8, Kalinga Nagar, Bhubaneswar, Odisha, India

Corresponding Author: Santosh Kumar Sahu Assistant Professor, Department of Orthopaedics, IMS and SUM Hospital, Bhubaneswar, Odisha, India

\section{Surveillance of organisms and their drug sensitivity patterns in orthopaedics post surgical patients at a tertiary care teaching hospital}

\author{
Sidhartha Samal, Santosh Kumar Sahu and Swayamprabha Sahoo
}

DOI: https://doi.org/10.22271/ortho.2019.v5.i4n.1771

\section{Abstract}

Background: Among the Health care associated infections (HAI), orthopaedic surgical site infections (OSSI) previously termed as post-operative wound infections are one of the most common HAI in low and middle income countries. Increase in OSSI is associated with increased morbidity, as well as mortality due to emergence of antimicrobial resistant pathogens. Understanding the pathogens implicated in causing the OSSIs and their antimicrobial sensitivity place a good role in reducing the mortality and morbidity.

Methods: A prospective study was conducted at a tertiary care hospital to all the patients admitted in Department of Orthopaedics for 2 years from January 2017 to December 2018. The demographic data, inclusion criteria and exclusion criteria, risk factors, clinical history, laboratory data with gram stain, culture results and antibiotic sensitivity of the isolates were collected.

Results: Two hundred patients were recruited in the study and the prevalence of OSSI in the study was $3.83 \%$. Patients who underwent emergency operations and diabetics were at higher risk of acquiring OSSI. The most commonly isolated pathogens in the study were Staphylococcus aureus, Escherichia coli, and Pseudomonas aeruginosa. Pseudomonas aeruginosa was most common isolate from orthopaedic cases of OSSI.

Conclusions: Study clearly explains the various causes and risk factors associated in development of OSSI. The study guides in the type of the organism isolated and possible antibiotic of choice in treatment and management of OSSI. The prevalence of OSSI was 3.83\%, which is comparable with some of the studies and lower than many of the studies.

Keywords: OSSI, antibiotic, drug resistant bacteria, MRSA, mortality, morbidity

\section{Introduction}

Among the Health care associated infections (HAI), surgical site infections (OSSI) previously termed as postoperative wound infections are one of the most common HAI in low and middle income countries. The prevalence of these infections varies widely ranging from $5-16 \%$. In India, based upon the various studies prevalence of OSSI varies between $5 \%$ and $24 \%$ [1]. OSSI are defined as an infection occurring within 30 days after a surgical operation (or within 1 year if an implant is left in place after procedure) and affecting either incision or deep tissues at the operation site ${ }^{[2]}$. Despite advances in OSSI control practices, like improved operating room ventilation, sterilization methods, use of barriers, surgical technique there has been an alarming rise in low and middle income countries. Increase in OSSI is associated with increased morbidity, as well as mortality due to emergence of antimicrobial resistant pathogens. Factors related to development of OSSI include patient related factors like smoking, diabetes etc. and also operationrelated factors like duration of surgery, type of surgery etc ${ }^{[3]}$. Thus the identification of these factors that cause and predict these infections continues to be an area of research. There are various strategies to minimize the OSSIs, and these can be interventions done before, during or after surgery ${ }^{[4]}$. Understanding the pathogens implicated in causing the OSSIs and their antimicrobial sensitivity place a good role in reducing the mortality and morbidity. Studies have shown an increase in the trend of OSSIs attributable to antimicrobial resistant pathogens such as MRSA. 
The present study was undertaken with an aim to identify the possible risk factors related to development of OSSIs and the common pathogens encountered in development of OSSIs. Identifying the pathogens and their antimicrobial sensitivity provides help in empirical management of OSSIs

\section{Methods}

A prospective cross sectional study was conducted at IMS and SUM Hospital with Medical Research Laboratory for a period of two years from January 2017 to December 2018. The study was carried out at orthopaedics wards and cabins of the hospital. All the cases that were identified with OSSI were included in the study. The study was approved by the institutional ethical committee of the college and all the procedures were conducted in accordance to ethical guidelines.

\section{Inclusion criteria}

All the age groups excluding the children $<5$ years, confirmed cases of OSSI (As per case definition) and who consented for the study.

\section{Exclusion criteria}

Infection occurring 30 days after the surgery, donor sites of split skin grafts and refusal to give consent for participating in the study.

\section{Case definition of OSSI}

Defined as per CDC Guidelines: OSSI was classified as superficial, deep incisional or organ/space infection with

- Purulent drainage with or without laboratory confirmation from the superficial or deep incision

- Organism isolated from an aseptically obtained culture of fluid or tissue from superficial or deep incision or organ/space

- Sign or symptoms of infection: Pain and tenderness, localized swelling, or heat

- Purulent drainage from the drain that is placed into the organ/space

- Diagnosis of OSSI by surgeon or attending physician ${ }^{[5]}$.

A total of 200 patients were recruited in the study and all the patients fulfilled the inclusion criteria. A structured questionnaire form consisting of demographic data, risk factors, past medical history, antibiotic usage history, and particulars of surgery, antibiotic prophylaxis was noted. Swabs were collected from the infected site as per standard guidelines, and collected before dressing was done. Swabs were transported immediately to the Medical Research Laboratory and processed immediately as per standard CLSI guidelines. The pathogens were isolated and identified by a battery of biochemical tests and antimicrobial susceptibility of the pathogen was performed as per CLSI Guidelines ${ }^{[6]}$.

For gram positive organisms susceptibility was tested against penicillin (10 unit), ampicillin $(10 \mu \mathrm{g})$, amoxicillin/ clavulanate $(20 / 10 \mu \mathrm{g})$, ceftriaxone $(30 \mu \mathrm{g})$, vancomycin $(30 \mu \mathrm{g})$, gentamycin $(10 \mu \mathrm{g})$, erythromycin $(15 \mu \mathrm{g})$, tetracycline $(30 \mu \mathrm{g})$ ciprofloxacin $(5 \mu \mathrm{g})$, clindamycin $(2 \mu \mathrm{g})$, triomethoprim/ sulfamethaxazole $\quad(1.25 / 23.75 \mu \mathrm{g})$ chloramphenicol $(30 \mu \mathrm{g})$, and Linezolid $(30 \mu \mathrm{g})$. Gram negative organisms were tested against ampicillin $(10 \mu \mathrm{g})$, amoxicillin/ clavulanate $(20 / 10 \mu \mathrm{g})$, ceftriaxone $(30 \mu \mathrm{g})$, ceftazidime $(30 \mu \mathrm{g})$, cefotaxime $(30 \mu \mathrm{g})$ gentamycin $(10 \mu \mathrm{g})$, tetracycline $(30 \mu \mathrm{g})$, ciprofloxacin $(5 \mu \mathrm{g})$, triomethoprim/ sulfamethaxazole $(1.25 / 23.75 \mu \mathrm{g})$, chloramphenicol $(30 \mu \mathrm{g})$, imipenem $(10 \mu \mathrm{g})$ and Meropenem $(10 \mu \mathrm{g})$ Methicillin resistance Staphylococcus aureus was determined by disc diffusion test using cefoxitin $(30 \mu \mathrm{g})$ disc and results were interpreted as per CLSI guidelines. Inducible clindamycin resistance was detected among Staphylococcus aureus by disc diffusion test using erythromycin $(15 \mu \mathrm{g})$ and $2 \mu \mathrm{g}$ of Clindamycin placed on Muller Hinton agar and observing the D-Zone as per CLSI guidelines.

\section{Statistical analysis}

Data was entered in Microsoft excel spread sheet and analyzed. Frequency distribution and two way tables were used to summarize the data and Chi-square test or Fishers Exact Test were used to determine the association between independent and dependent variables, $p$ values of $<0.05$ were considered significant.

\section{Results}

The most common isolated pathogen was Staphylococcus aureus 38 (28.35\%), followed by Klebsiella spp. 21 (15.68\%) and Escherichia coli $16(11.95 \%)$. There was only one $(0.74 \%)$ isolate of Mycobacterium tuberculosis (Table 1, Fig $1)$.

Table 1: Bacteria isolated from the orthopaedic surgery infections

\begin{tabular}{|c|c|c|}
\hline Organisms & Isolated pathogens & percentage \\
\hline Staphylococcus aureus & 38 & $28.35 \%$ \\
\hline Coagulase negative Staphylococcus & 11 & $8.20 \%$ \\
\hline Enterococcus spp. & 3 & $2.23 \%$ \\
\hline Klebsiellaspp & 21 & $15.68 \%$ \\
\hline Pseudomonas aeruginosa & 13 & $9.71 \%$ \\
\hline Escherichia coli & 16 & $11.95 \%$ \\
\hline Acinetobacter spp. & 11 & $8.20 \%$ \\
\hline Citrobacter spp. & 9 & $6.71 \%$ \\
\hline Enterobacter spp. & 7 & $5.23 \%$ \\
\hline M. tuberculosis & 1 & $0.74 \%$ \\
\hline Proteus spp. & 4 & $2.98 \%$ \\
\hline Total & 134 & $100 \%$ \\
\hline
\end{tabular}

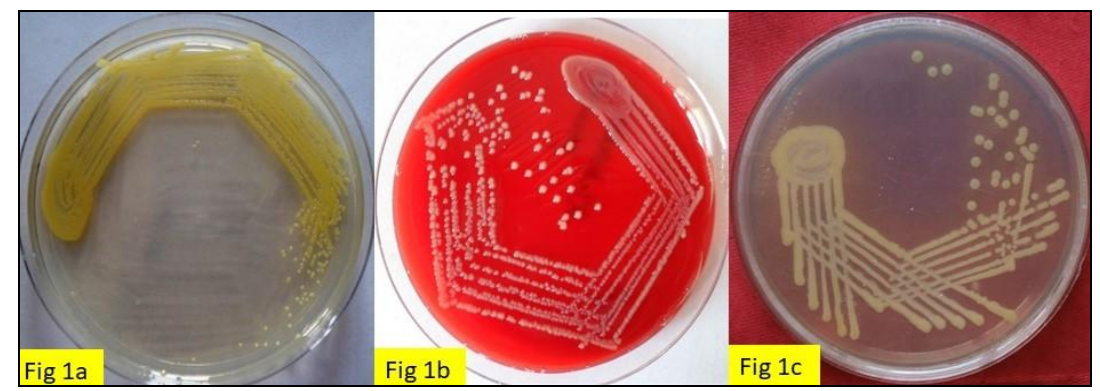

Fig 1: a) S. aureus on nutrient agar, b) Klebsiella spp on blood agar, c) E. coli on nutrient agar. Majority 69 (51.49\%) of the patients was in the early post-operative period. Staphylococcus aureus $38(28.35 \%)$ was the most common isolated pathogen in the early $21(15.67 \%)$, delayed 13 $(9.70 \%)$ and late 4 (2.98\%) post-operative period (Table 2$)$. 
Table 2: Bacteria isolated from the orthopaedic surgery wounds with respect to time duration

\begin{tabular}{|c|c|c|c|c|}
\hline Organisms & $\begin{array}{c}\text { Early } \\
(<\mathbf{2} \text { weeks) }\end{array}$ & $\begin{array}{c}\text { Delayed } \\
(\mathbf{2 - 1 0} \text { weeks) }\end{array}$ & $\begin{array}{c}\text { Late } \\
(\mathbf{1 0} \text { weeks })\end{array}$ & Total \\
\hline S. aureus & $21(15.67 \%)$ & $13(9.70 \%)$ & $4(2.98 \%)$ & $38(28.35 \%)$ \\
\hline CoNS & $5(3.73 \%)$ & $4(2.98 \%)$ & $2(1.49 \%)$ & $11(8.21 \%)$ \\
\hline Enterococcus spp. & $1(0.75 \%)$ & $2(1.49 \%)$ & $0(0 \%)$ & $3(2.24 \%)$ \\
\hline Klebsiella spp. & $11(8.21 \%)$ & $8(5.97 \%)$ & $2(1.49 \%)$ & $21(15.67 \%)$ \\
\hline P. aeruginosa & $6(4.48 \%)$ & $5(3.73 \%)$ & $2(1.49 \%)$ & $13(9.70 \%)$ \\
\hline E. Coli & $9(6.72 \%)$ & $6(4.48 \%)$ & $1(0.75 \%)$ & $16(11.94 \%)$ \\
\hline Acinetobacter spp. & $6(4.48 \%)$ & $4(2.98 \%)$ & $1(0.75 \%)$ & $11(8.21 \%)$ \\
\hline Citrobacter spp. & $5(3.73 \%)$ & $3(2.24 \%)$ & $1(0.75 \%)$ & $9(6.71 \%)$ \\
\hline Enterobacter spp. & $3(2.24 \%)$ & $3(2.24 \%)$ & $1(0.75 \%)$ & $7(5.22 \%)$ \\
\hline Proteus spp. & $2(1.49 \%)$ & $2(1.49 \%)$ & $0(0 \%)$ & $4(2.98 \%)$ \\
\hline M. tuberculosis & $0(0 \%)$ & $1(0.75 \%)$ & $0(0 \%)$ & $1(0.74 \%)$ \\
\hline Total & $69(51.49 \%)$ & $51(38.06 \%)$ & $14(10.45 \%)$ & $134(100 \%)$ \\
\hline
\end{tabular}

Most of the Gram-positive isolates were more susceptible to linezolid, vancomycin and tigecycline (Table 3 ).

Table 3: Antibiotic sensitivity patterns of gram positive bacteria

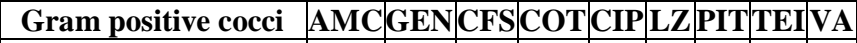

\begin{tabular}{|c|c|c|c|c|c|c|c|c|c|}
\hline S. aureus $(\mathrm{n}=38)$ & 56 & 60 & 74 & 52 & 46 & 92 & 88 & 100 & 100 \\
\hline CoNS $(\mathrm{n}=11)$ & 58 & 54 & 68 & 56 & 42 & 100 & 87 & 100 & 100 \\
\hline Enterocuccus $\mathrm{spp} .(\mathrm{n}=3)$ & 33 & 33 & 33 & 33 & 33 & 66 & 100 & 100 & 66 \\
\hline
\end{tabular}

The Gram-negative isolates showed maximum susceptibility to imipenem (IPM), cefoperazone-sulbactam (CFS) and piperacillin-tazobactam (PIT) combination of antimicrobial agents (Table 4).

Table 4: Antibiotic sensitivity patterns of gram Negative bacteria

\begin{tabular}{|c|c|c|c|c|c|c|c|c|c|}
\hline Gram negative bacilli & AMC & CAZ & CFS & COT & CFM & CIP & GEN & PIT & IPM \\
\hline Klebsiella spp. $(\mathrm{n}=21)$ & 47 & 29 & 76 & 48 & 63 & 58 & 62 & 80 & 86 \\
\hline Pseudomonas aeruginosa $(\mathrm{n}=13)$ & 69 & 48 & 77 & 58 & 52 & 60 & 67 & 76 & 88 \\
\hline Acinetobacter $\mathrm{spp} .(\mathrm{n}=11)$ & 36 & 62 & 80 & 62 & 63 & 62 & 64 & 74 & 92 \\
\hline E. $\operatorname{coli}(\mathrm{n}=16)$ & 36 & 62 & 87 & 52 & 56 & 38 & 77 & 82 & 90 \\
\hline Citrobacter spp. $(\mathrm{n}=9)$ & 44 & 57 & 79 & 72 & 56 & 57 & 65 & 82 & 94 \\
\hline Enterobacter $\mathrm{spp} .(\mathrm{n}=7)$ & 45 & 70 & 86 & 74 & 71 & 62 & 73 & 87 & 96 \\
\hline Proteus spp. $(\mathrm{n}=4)$ & 25 & 50 & 75 & 25 & 50 & 50 & 75 & 75 & 100 \\
\hline
\end{tabular}

\section{Discussion}

In the present study conducted in a teaching hospital, the incidence of OSSI was $3.83 \%$. OSSI in the present study was defined as per CDC guidelines. However, the incidence of OSSI is influenced by various operation related factors (type of operation performed, nature of operation, Anesthesia type etc.), physical factors and patient related factors (age of patient, sex of patient, co morbidities etc.) etc. The incidence in our study was on par with findings of Murthy $\mathrm{R}$ et al. who reported $4.2 \%$ as incidence of OSSI in their study ${ }^{[7]}$, but very low when compared to study done in Georgia who reported the overall incidence as $16.7 \%{ }^{[8]}$. This variation can be explained by different factors involved in the study analysis like place of study, type of operation etc. In our study, males were predominant $(61 \%)$ than females indicating more number of surgeries was done on males than females. These findings were on par with findings of Tanner $\mathrm{J}$ et al. The rate of OSSI was more in males than females in our study ${ }^{[9]}$.

The common age group in the study was 18-26 years followed by 46-55 years which is on par with the findings of Khairy GA et al. but contrary to findings of Astagneau Leaper et al. who reported OSSI more in age group $>65$ years ${ }^{[10,11]}$. The rate of OSSI were higher in emergency surgeries than elective procedures as described by many other studies also $(56 \%$ versus $44 \%)^{[12,13]}$. This can be due to the reason like emergency surgeries lack regular pre-operative preparation and involve mostly abdominal and intestinal surgeries which are contaminated surgeries. As reported in many studies, rate of OSSI was higher among uncontrolled diabetics than controlled and non-diabetics in our study. This observation was on par with findings of Neumayer et al. ${ }^{[14]}$.

As reported from this study, OSSI was higher in cases of abdominal surgeries (Hernia and Intestinal surgeries) than in other surgeries. Others also observed the same findings in their studies. The rate of OSSI was higher in contaminated surgeries followed in order by dirty, clean contaminated and clean surgeries. Similar findings were reported in the findings of Rosentha et al. in his study ${ }^{[15]}$.
In the present study, the commonest bacterial isolate was staphylococcus aureus (25.34\%) from various OSSI which coincides with the findings of Kownhar $\mathrm{H}$ who reported the $37 \%$ of isolates as $S$. aureus among which $27 \%$ were MRSA [16]. Majority of $S$. aureus was isolated from cases of orthopaedic OSSI and procedure was open fractures with fixation followed by LSCS surgeries among who underwent emergency procedure. These findings were on par with findings of Burns TC et al. ${ }^{[17]}$ However, the incidence of MRSA was significantly higher in our study (37\%) when compared with the findings of Burns TC et al., Kamat U et al. [18] Various other studies have reported Pseudomonas aeruginosa and Escherichia coli as major isolates in their studies. However, the type of isolate is dependable upon variable physical and operational factors (Type of operation etc.). Coagulase negative Staphylococcus was the major isolate recovered from cases of OSSI following LSCS.

In present study among Gram negative isolates, Escherichia coli and Pseudomonas aeruginosa were predominant isolates as per findings of many studies. E. coli was the major isolate from intestinal surgeries and abdominal surgeries as mentioned in the study of Suljagic V et al. ${ }^{[19]}$ Regarding the frequency of isolation of organisms from different surgical units, E. coli and Klebsiella pneumoniae were common from surgical wards and Pseudomonas aeruginosa from orthopaedic wards. These observations were similar to findings of Bericon et al. and Anvikar et al. ${ }^{[20,21]}$.

In the present study, $S$. aureus was highly resistant to pencillin and ampicillin which concurs with many of the studies reported recently [22, 23]. A notifiable finding in our study was a greater proportion of $S$. aureus strains, exhibited resistance to Amoxyclaulanic acid which indicates a gradual decline in the use of this drug for treatment of OSSI caused by $S$. aureus. The current study documented a higher rate of methicillin resistance among S. aureus (37\%), which signifies the increasing trend of MRSA infection and wide spread reports locally and globally confirms the findings of our study. Resistance was not observed to vancomycin and linezolid in our study. 
Cons were isolated and all the strains in the study were resistant to penicillin and ampicillin. None were resistant to vancomycin and linezolid. Similar findings were observed in the reports of Cantlon CA et al. who reported CONS as a major isolate from OSSI ${ }^{[24]}$. Few of the strains of $S$. aureus exhibited Clindamycin resistance which suggests a thorough screening of isolates in treatment of Staphylococcal infections.

In this study, gram negative isolates exhibited maximum degree of resistance to commonly used low generation antibiotics and these findings were in consistent with many other studies globally. The reason is these antibiotics are widely prescribed in empirical treatment of various infections in our setting. So, usage of these drugs in treatment of OSSI should be monitored and switched over to other drugs in nonresponsive cases. Most of the isolates in the study exhibited greater degree of resistance to Amoxyclavulanic acid than expected and this signifies a gradual shift of organisms towards antibiotic choice. Most of the gram-negative isolates were multi drug resistant and exhibited maximum sensitivity to carbapenems and Piepracillin/tazobactum. Moderate degree of sensitivity was noted to higher generation cephalosporins by Pseudomonas aeruginosa and $100 \%$ sensitivity by Proteus $s p$. These findings suggest usage of higher generation cephalosporins and carbapenems as a primary choice of antibiotics in treatment of OSSI.

\section{Conclusion}

Study clearly explains the various causes and risk factors associated in development of OSSI. The study guides in the type of the organism isolated and possible antibiotic of choice in treatment and management of OSSI. The prevalence of OSSI was $3.83 \%$, which is comparable with some of the studies and lower than many of the studies. E. coli was the commonest isolate from intestinal surgeries and Pseudomonas aeruginosa from orthopedic surgeries. The rate of OSSI was more in emergency operations and also in dirty wound than clean wounds.

\section{References}

1. Pathak A, Saliba EA, Sharma S, Mahadik VK, Shah H, Lundborg CS. Incidence and factors associated with surgical site infections in a teaching hospital in Ujjain, India. Am J Infect Control, 2014, 42e11-5.

2. Mangram AJ, Horan TC, Pearson ML, Silver LC, Jarvis WR. Guideline for Prevention of Surgical Site Infection. Centers for disease control and prevention (CDC) hospital infection control practices advisory committee. Am J Infect Control. 1999; 27:97-132.

3. Barie PS. Surgical site infections: epidemiology and prevention. Surg Infect. 2002; 3(1):9-21.

4. Siguan SS, Ang BS, Pala IM, Baclig RM. Aerobic surgical infection: a surveillance on microbiological etiology and antimicrobial sensitivity pattern of commonly used antibiotics. Philipp J Microbiol Infect Dis. 1990; 19:27-33.

5. Garner JS. The CDC hospital infection control practices advisory committee. Am J Infect Control. 1993; 21:1602.

6. CLSI. Performance standards for antimicrobial susceptibility testing; twentieth informational supplement CLSI document M100-S20 Wayne, PA: Clinical and Laboratory Standards Institute, 2010.

7. Murthy R, Sengupta S, Maya N, Shivananda PG. Incidence of postoperative wound infection and their antibiogram in a teaching and referral hospital. Indian $\mathbf{J}$ Med Sci. 1998; 52:553-5.

8. Brown S, Kurtsikashvili G, Alonso Echanove J, Ghadua M, Ahmeteli L, Bochoidze T, et al. Prevalence and predictors of surgical site infection in Tbilisi, Republic of Georgia. J Hosp Infect. 2007; 66:160-6.

9. Tanner J, Khan D, Aplin C, Ball J, Thomas M, Bankart J. Post discharge Surveillance to identify colorectal surgical site infection rates and related costs. J Hosp Infect. 2009; 72:243-50.

10. Leaper DJ. Surgical-site infection. Br J Surg. 2010; 97:1601-2.

11. Astagneau P, Heriteau FI, Daniel F, Parniex P, Venier AG, Malvaud S, et al. Coignard for the ISO-RAISIN Steering Group. Reducing surgical site infection incidence through a network: results from the French ISO-RAISIN surveillance system. J Hosp Infect. 2009; 72:127-34.

12. Kamat US, Fereirra AMA, Kulkarni MS, Mothgare DD. A prospective study of surgical site infections in a teaching hospital in Goa. Indian J Surg. 2008; 70:120-4.

13. Jawaid M, Masood Z, Iqbal SA. Postoperative complications in a general surgical ward of a teaching hospital. Pak J Med Sci. 2006; 22:171-5.

14. Neumayer L, Hosokawa P, Itani K, ElTamer M, Henderson WG, Khuri SF. Multivariable predictors of postoperative surgical site infection after general and vascular surgery: Results from the patient safety in surgery study. J Am Coll Surg. 2007; 204:1178-87.

15. Rosenthal R, Weber WP, Marcel Z, Misteli H, Reck S, Oertli D, et al. Impact of surgical training on incidence of surgical site infection. World J Surg. 2009; 33:1165-73.

16. Kownhar H, Shankar EM, Vignesh R, Sekar R, Velu V, Rao UA. High isolation rate of staphylococcus aureus from surgical site infections in an Indian Hospital. J Antimicrob Chemoth. 2008; 3:758-60.

17. Burns TC, Stinner DJ, Mack AW, Potter BK, Beer R, Eckel TT, et al. Microbiology and injury Characteristics in severe open tibia fractures from combat. J Trauma Acute Care Surg. 2012; 72(4):1062-7.

18. Kamat U, Ferreira A, Savio R, Motghare D. Antimicrobial resistance among Nosocomial isolates in a teaching hospital in Goa. Indian J Community Med. 2008; 33:89-92.

19. Suljagic V, Jevtic M, Djordjevic B, Jovelic A. Surgical site infections in a tertiary health care center: prospective cohort study. Surg Today. 2010; 40:763-41.

20. Bercion R, Gaudeuille A, Mapouka PA, Behounde T, Guetahoun Y. Surgical site infection survey in the orthopaedic surgery department of the Hopitalcommunautaire de Bangui, Central African Republic. Bull Soc Pathol Exot. 2007; 100:197-200.

21. Anvikar AR, Deshmukh A, Karyakarte RP, Damle AS, Patwardhan NS, Malik AK, et al. One year prospective study of 3280. Surg Wounds. 1999; 17:129-32.

22. Andhoga J, Macharia AG, Maikuma IR, Wanyonyi ZS, Ayumba BR, Kakai R. Aerobic pathogenic bacteria in post-operative wounds at Moi Teaching and Referral Hospital. East Afr Med J. 2002; 79:640-4.

23. Anguzu JR, Olila D. Drug sensitivity patterns of bacterial isolates from septic post- operative wounds in a regional referral hospital in Uganda. Afr Health Sci. 2007; 7:14854.

24. Cantlon CA, Stemper ME. Schwan WR, Hoffman MA, Qutaishat SS. Significant pathogens isolated from 
surgical site infections at a community hospital in the Midwest. Am J Infect Control. 2006; 34526-9.

25. Arya M, Arya PK, Biswas D, Prasad R. Antimicrobial susceptibility pattern of bacterial isolates from postoperative wound infections. Indian J Pathol Microbiol. 2005; 48:266-9. 